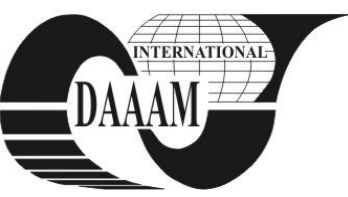

\title{
THE FLOW OF THERMAL ENERGY FROM GASES OF ELECTRIC FURNACE IN THE CHARGE OF ROTARY FURNACE
}

\author{
TERZIQI, A[vni] K[ahriman]; MULLIQI, I[smet] S[ejdi]; BAJRAKTARI, B[ekim] V[eli] \& MEHUSH RIFAT, \\ A[liu]
}

\begin{abstract}
Increased of fuels prices and environmental pollution highlights the necessity to become their maximum utilization. Even during the process of obtaining ferronickel in electric furnaces such a possibility exists. In this case the energy which contains gases at the exit of electric furnace can be used for heating and various before heating within the complex of the "New Company Ferronickel". In this paper is developed the model of using these gases for the purpose of heating in rotary furnace. Working model can be used in expansion of general model for rationalization of energy use in electric furnaces process for obtaining ferronickel.
\end{abstract}

Key words: electrical furnace, rotary furnace, gases, heating

\section{INTRODUCTION}

Electric furnace gases (EF) in the industrial complex of "Ferronickel" in Kosovo, currently cast directly into the atmosphere, without any preliminary treatment. In this way, the thermal energy contained in these gases remains untapped.

In order to model of use of the thermal energy of these gases to be more accurate, will be used measures taken of the parameters of gases in the chimney. Results of measurements of the concentration of the components of gases, and the gas flows to the regime for electric furnaces $24 M W$ and $33 M W$ are given as input value of model.

Measurements of concentrations of gases components are made with the instrument "Maihack" with detector with infrared ray and with instrument IMR. Gas flow measurements are made with the Pitott -Prandlt tube.

\section{TEMPERATURE OF GASES OF EF AT THE EXIT OF CONVEYOR TUBE}

The concentration of the thermal energy flows (Beqiri, 1996) in electric furnace gases (EF) in entrance and exit of conveyer tube with length $\mathrm{L}$ is:

$$
\begin{aligned}
& \left(E_{\tau} / L\right)_{1}=\left(m_{S} / L\right)_{1} C_{p_{\text {g.EF }}} T_{1} \\
& \left(E_{\tau} / L\right)_{2}=\left(m_{S} / L\right)_{2} C_{P_{\text {g.EF }}} T_{2}
\end{aligned}
$$

Meanwhile for the tube through which transported the gases of electric furnace with length $L$, the flow of the thermal energy in its output will be calculated according to equations:

$$
\begin{gathered}
\left(E_{\tau}\right)_{2}=\left(E_{\tau}\right)_{1}-q_{c+c+r} \\
q_{c+c+r}=q_{L, c+c+r} L \\
\left(E_{\tau}\right)_{2}=\left(E_{\tau}\right)_{1}-q_{L, c+c+r} L
\end{gathered}
$$

where are: $q_{c+c+r}$ - heat flow which loses in the environment with conduction, convection and radiation,

$q_{L, c+c+r}-$ Heat flow, in units of length, which loses in the environment with conduction, convection and radiation,
$\left(E_{\tau}\right)_{1}-$ the thermal energy flow in the entrance of the conveyor tube,

$\left(E_{\tau}\right)_{2}-$ the thermal energy flow in the exit of the conveyor tube, From equation (2) determined the gases temperature at the exit of conveyor tube, according to equation:

$$
T_{2}=\left(E_{\tau}\right)_{2} /\left(m_{S} C_{P_{g, E F}}\right)
$$

Based on the equations (1) and (2), for the regime $24 M W$ and $33 M W$ can be determined the dependence of the thermal energy flow and temperature of gases of electric furnace in the exit of conveyor tube for different lengths of this tube up to the entrance of rotary furnace (RF) (fig. 1 and fig. 2).

While the reduction of value of the gases temperature depending on the length of the conveyor tube is given in fig. 3 .

\section{THE FLOW OF THE THERMAL ENERGY FROM THE EF GASES IN THE CHARGE OF RF}

The charge which enters into rotary furnace consists of nickel ore, limestone and lignite, is with average temperature during the year $T_{\text {sh. }}=283.15 \mathrm{~K}$.

While the flow of the heat, which is carried from gases of electric furnace in rotary furnace can be computes by the following equation (Sacadura, 1993):

$$
q^{\prime}=m_{S} C_{P_{g, E F}}\left(T_{2}-T_{c h}\right)
$$

The decrease of heat flows of gases in rotary furnace, depending on the length of conveyor tube, for regime $24 M \mathrm{~W}$ and $33 M W$ is shown in fig. 4 .

Total energy of gases brought by EF in RF not consists only in the thermal energy which is contained in gases, but also by their thermal capacity, which is the result of carbon monoxide contained in these gases.

The low thermal ability of fuel and low thermal ability of gases (Coulson, \& Richardson 1978) determined by equation:

$$
\begin{gathered}
H_{l_{\text {mazut }}}=33900 c+119710 h-17800 b+10450 s-2510 w \\
H_{\lg F E}=12644 c o
\end{gathered}
$$

Total energy that gases bring from electric furnaces in the rotary furnace consists of heat generated, from low thermal ability and thermal energy contained in the unit of measure:

$$
E_{T}=H_{l g . E F}+q^{\prime} / m_{s}
$$

Based on equation (10) can be determined the total energy values that electric furnace gases bring in rotary furnace for various lengths of conveyor tube (see figure 5). 
In the case when will be used only thermal energy equivalence with low thermal ability of electric furnace gases, saving of fuel for the working regime $24 M W$ and $33 M W$ will be compute:

$$
H_{l g . E F} / H_{l \text { fuel }}
$$

If used the total energetic flow of EF gases, the fuel savings will depend on the length of conveyor tube between $\mathrm{EF}$ and RF (fig. 6).

\section{CALCULATIONS AND RESULTS}

Input values in the model are: $\lambda_{\text {st. }}=59.313 \mathrm{~W} / \mathrm{mK}$. $\lambda_{\text {ins. }}=0.037 \mathrm{~W} / \mathrm{mK}, \quad \delta_{\text {ins. }}=0.05 \mathrm{~m} ; \quad \lambda_{\text {int. }} \quad=229.111 \mathrm{~W} / \mathrm{mK}$, $\delta_{\text {int. }}=0.0008 \mathrm{~m}, d_{1}=0.16 \mathrm{~m}, d_{2}=0.17 \mathrm{~m}, \mathrm{~d}_{3}=0.270 \mathrm{~m}, \mathrm{~d}_{4}=0.2716 \mathrm{~m}$, $\mathrm{T}_{\text {envir. }}=283.15 K, \quad T_{\text {internal }}=303.15 K, \quad d_{\text {chimney }}=0.735 \mathrm{~m}, w_{1}$ $=11.67 \mathrm{~m} / \mathrm{s}, \rho_{l}=0.365 \mathrm{~kg} / \mathrm{m}^{3}, \lambda_{g E F}=0.09575 \mathrm{~W} / \mathrm{mK}, p_{g}=101325$ $\mathrm{Pa}, \quad T_{g, 33 M W}=1123.15 \mathrm{~K}, \quad T_{g, 24 M W}=1149.15 \mathrm{~K}, \quad \Delta \mathrm{T}=20 \mathrm{~K}$, $\beta=0.00341, \varepsilon_{l}=0.055, C=0.135, n=0.3333, M_{C O}=28, M_{C O 2}=44$, $M_{S O 2}=64 ; M_{O 2}=32 ; M_{N O}=30 ; M_{N O 2}=46 ; v_{\text {air }}=15.0610^{6} \mathrm{~m}^{2} / \mathrm{s}$, $\lambda_{\text {air }}=0.02593 \mathrm{~W} / \mathrm{mK}, P r_{\text {air }}=0.703, \rho_{\text {air }}=1.205 \mathrm{~kg} / \mathrm{m}^{3}, C p_{C O}=$ $1114.425 \mathrm{~J} / \mathrm{kgK}, C p_{\mathrm{CO} 2}=1094.85 \mathrm{~J} / \mathrm{kgK}, C p_{\mathrm{O}_{2}}=1020.75 \mathrm{~J} / \mathrm{kgK}$, $C p_{S_{O} 2}=767.25 \mathrm{~J} / \mathrm{kgK}, \mu_{\mathrm{CO}}=4.5 \times 10^{5} \mathrm{~Pa}, \mu_{\mathrm{CO} 2}=4.6 \times 10^{-5} \mathrm{~Pa}, \mu_{O 2}=$ $5.1 \times 10^{-5} \mathrm{~Pa}, \mu_{\mathrm{SO} 2}=3.8 \times 10^{-5} \mathrm{~Pa}$ (Michael \& Howard 2004). While the results calculated by the model are given in figure 1 - fig. 6 .

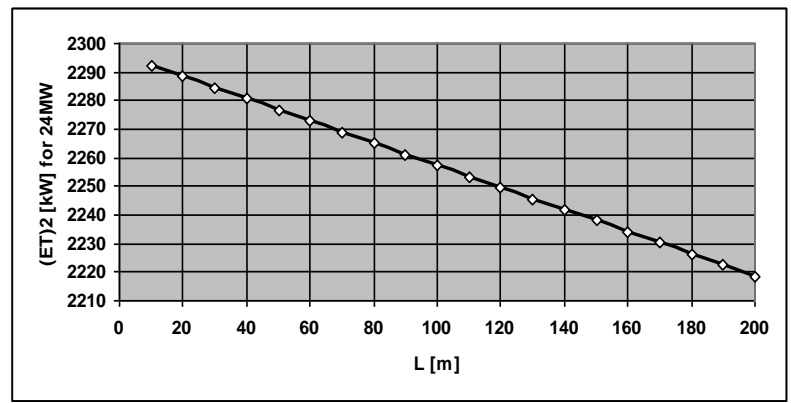

Fig. 1. $\left(E_{T}\right)_{2}=f(L)$ for $24 M W$

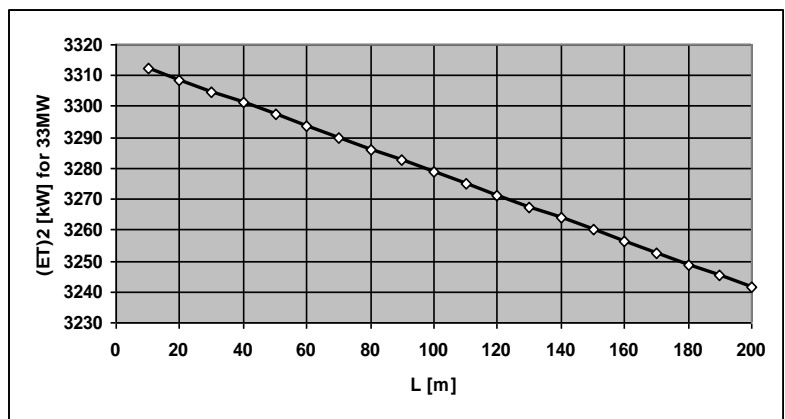

Fig. 2. $\left(E_{T}\right)_{2}=f(L)$ for $33 M W$

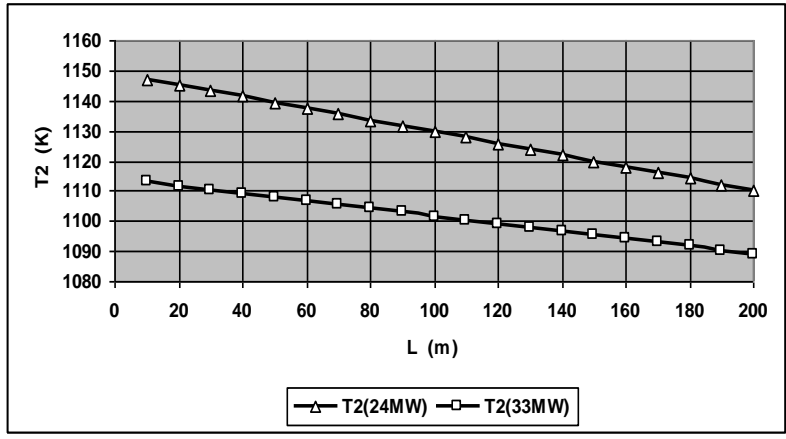

Fig. 3. $T_{2}=f(L)$ for $24 M W$ and $33 M W$

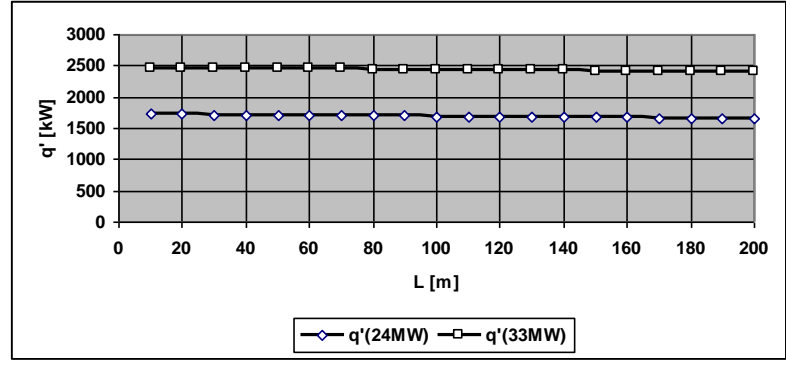

Fig. 4. $q^{\prime}=f(L)$ for $24 M W$ and $33 M W$

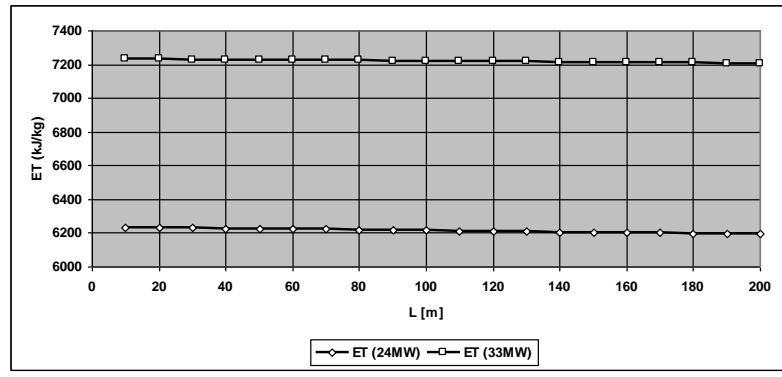

Fig. 5. $E_{T}=f(L)$ for $24 M W$ and $33 M W$

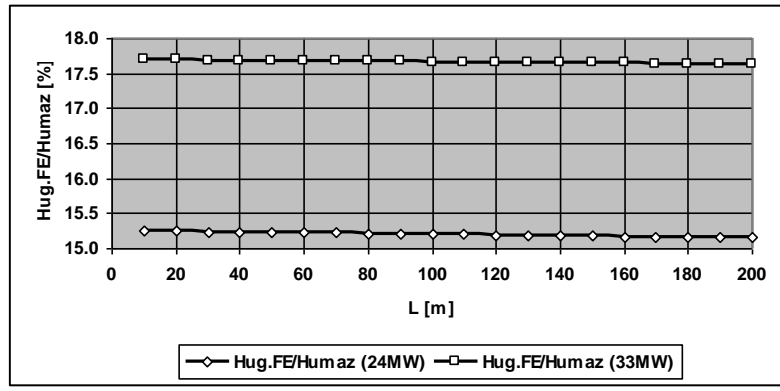

Fig. 6. $H_{l g . E F} / H_{\text {fuel }}=f(L)$ forr $24 M W$ and $33 M W$

\section{CONCLUSION}

The flow of the total thermal energy, including the power generated from thermal capacity that electric furnace gases submit charges in RF marks a decrease depending on the length of tube.

While the flow of the total thermal energy delivered during the working regime $33 \mathrm{MW}$ is higher than for working regime $24 M W$.

In the case when will be used only thermal energy equivalence with low thermal ability of electric furnace gases, the fuel savings for working regime $24 M W$ will be compute $12.9 \%$, while for working regime $33 \mathrm{MW}$ this savings will be compute $15.5 \%$.

In the case when will be used as thermal energy equivalence with low thermal ability of electric furnace gases, as well as the significant energy of these gases, the fuel savings for working regime $24 M W$ will be compute about $15 \%$, while for working regime $33 \mathrm{MW}$ savings will be compute about $18 \%$.

\section{REFERENCES}

Coulson, J. \& Richardson,F. (1978). Chemical Engineering, 3rd Edition, Vols. 1, 2, Pergamon, Oxford

Michael, J. \& Howard, N. (2004). Fundamental of Engineering Thermodynamics, John Wiley, ISBN 0-471-27471-2, Hoboke

Beqiri, E. (1996). High Course of heat transmissions, Prishtina Sacadura, J. (1993) Knowledge for thermal transfer, TEC\&DOC, ISBN 2-85206-618-1, Paris 